\title{
Young's modulus of (Ti,Si)N films by surface acoustic waves and indentation techniques
}

\author{
F. Vaz ${ }^{\mathrm{a}}$, S. Carvalho ${ }^{\mathrm{a}}$, L. Rebouta ${ }^{\mathrm{a}} *$, M.Z. Silva ${ }^{\mathrm{a}}$, A. Paúl ${ }^{\mathrm{b}}$, D. Schneider ${ }^{\mathrm{c}}$ \\ ${ }^{a}$ Universidade do Minho, Dept. Física, Azurém, 4800-058 Guimarães, Portugal \\ ${ }^{\mathrm{b}}$ ITN, Departamento de Física, E.N. 10, 2686-953 Sacavém, Portugal \\ ${ }^{\mathrm{c}}$ Fraunhofer Institut für Werkstoffphysik und Schichttechnologie, D-01277 Dresden, Germany
}

Received 24 July 2001; received in revised form 4 January 2002; accepted 13 February 2002

\begin{abstract}
$\mathrm{Ti}_{1-x} \mathrm{Si}_{x} \mathrm{~N}_{y}$ films with $\mathrm{Si}$ contents up to 17.5 at.\% and $\mathrm{N}$ contents close to 50 at.\% were prepared by r.f. reactive magnetron sputtering. Film densities are within the range $3.4-5.1 \mathrm{~g} / \mathrm{cm}^{3}$. X-Ray diffraction patterns indicated the formation of two crystalline phases. In the case of low surface mobility, a metastable $(\mathrm{Ti}, \mathrm{Si}) \mathrm{N}$ phase was formed, where $\mathrm{Si}$ atoms occupied $\mathrm{Ti}$ positions. With increasing surface mobility, a crystalline TiN phase was observed. This behaviour may be explained by the occurrence of $\mathrm{Si}_{3} \mathrm{~N}_{4}$ segregation, leading to the formation of a nanocomposite film of the type nc-TiN/nc- $(\mathrm{Ti}, \mathrm{Si}) \mathrm{N} / \mathrm{a}-\mathrm{Si}_{3} \mathrm{~N}_{4}$, although the presence of $\mathrm{Si}_{3} \mathrm{~N}_{4}$ phase is difficult to prove. In some of the films, a mixture of the $(\mathrm{Ti}, \mathrm{Si}) \mathrm{N}$ metastable phase with the TiN phase was observed, which indicates that the segregation of both $\mathrm{TiN}$ and $\mathrm{Si}_{3} \mathrm{~N}_{4}$ phases is not complete. The Young's modulus, $E_{\mathrm{f}}$, of each coating was evaluated using both indentation tests and the surface acoustic waves (SAW) method. For most samples, the results obtained by these two methods are in good agreement. Some differences were observed in films prepared with a bias voltage of $-50 \mathrm{~V}$ and Si contents higher than 5.9 at.\%. For these samples, indentation values of approximately $10-20 \%$ higher than those obtained from SAW were found. This discrepancy is related to the nanostructure of these coatings, and it should be pointed out that the SAW results are strongly correlated with the density of the material. (c) 2002 Elsevier Science B.V. All rights reserved.
\end{abstract}

Keywords: Nitrides; Sputtering; Elastic properties; Structural properties

\section{Introduction}

The search for new superhard materials has increased considerably in the last few years, being an important area of technological research. These new materials, based on grain refinement, are commonly called nanostructured materials and exhibit unusual mechanical and structural properties [1-4]. A new concept for superhard materials, whose basic idea is to avoid the usual mechanisms leading to the fracture of crystalline (multiplication, movement and pile-up of dislocations) and amorphous (growth of microcracks) materials has reached a considerable development [3,5]. Basically, this concept involves the preparation of a two-phase system, composed of a nanocrystalline material embedded in an

\footnotetext{
*Corresponding author. Tel.: +351-253-510151; fax: +351-253510153.

E-mail address: rebouta@fisica.uminho.pt (L. Rebouta).
}

amorphous matrix [5,6], where the ternary $(\mathrm{TM}, \mathrm{Si}) \mathrm{N}$ ( $\mathrm{TM}=$ transition metal, e.g. Ti, V, W, etc.) is one of the most well-known examples [3,5,7-13]. In this respect, the result of $\mathrm{Si}$ addition to the TiN matrix has been acclaimed as one of the most promising approaches. This system has been widely prepared by chemical vapour deposition (CVD) methods [3,5,8,9], although they were at first prepared by plasma vapour deposition (PVD) (reactive sputtering) from composite targets $\left(\mathrm{Ti}_{x} \mathrm{Si}_{y}\right)$ [7,14]. These films are said to result in a twophase alloy of TiN grains embedded in an amorphous silicon nitride matrix $[13,14]$. The outstanding values of hardness (higher than $50 \mathrm{GPa}$ ) revealed by this system are attracting the attention of several research teams. The increase in hardness for these composites is directly related with the decrease in both TiN crystallite size and the presence of the referred amorphous tissue. Beyond hardness, which has been widely studied and character- 
ised, the knowledge of other mechanical properties, such as the Young's modulus, is not so good. Moreover, the comparative discussion of the results obtained by different techniques is far from being complete.

With this in mind, indentation and SAW techniques were used to measure the Young's modulus of samples within the referred $(\mathrm{Ti}, \mathrm{Si}) \mathrm{N}$ system. Although the indentation technique is commonly used for determining the Young's modulus of coatings, the comprehensive mechanical characterisation of thin hard coatings with unusual microstructure and mechanical properties, demands the application of other mechanical test methods beyond the traditional one. The laser-acoustic method, based on surface acoustic waves, is a new alternative method to measure Young's modulus of thin hard and super-hard films. The Young's modulus of the film is essential to understand the mechanical behaviour of the material. This property represents the stiffness of the material that depends on the inter-atomic forces and is, therefore, a sensitive indicator for varying bonding structures. This is of special interest for thin films deposited from extreme energetic condition with the objective of getting new remarkable properties. The laser-acoustic method measures the dependence of the surface wave phase velocity on frequency (dispersion curve). This dispersion curve is then used to determine the film modulus $E_{\mathrm{f}}$, by fitting a theoretical curve deduced from the inverse solution of surface wave dispersion relation in a coated material. For this, a nonlinear regression method is usually used [15].

\section{Theoretical background}

\subsection{Surface acoustic waves}

The surface acoustic wave (SAW) is an acoustic wave mode, whose motion is essentially confined to a region within a depth of approximately one wavelength. Thin film testing requires high frequency waves, which have low penetration depth. Nevertheless, the penetration depth must not be smaller than the film thickness. The surface wave is very sensitive to the presence and characteristics of the surface coatings, even when they are much thinner than the penetration depth of the wave. The propagation velocity of the surface waves, $c$, in a homogeneous isotropic medium is related to the Young's modulus, $E$, the Poisson's ratio, $\nu$, and the density, $\rho$, by the following approximate relation [16]:

$c=\frac{0.87+1.12 v}{1+v} \sqrt{\frac{E}{2 \rho(1+v)}}$

In this case the velocity does not depend on the frequency.

For a material consisting of a homogeneous isotropic film on a homogeneous isotropic substrate, the surface wave velocity is determined by the Young's modulus of both film and substrate, $E_{\mathrm{f}}$ and $E_{\mathrm{s}}$, their Poisson's ratios $\nu_{\mathrm{f}}$ and $\nu_{\mathrm{s}}$, and densities $\rho_{\mathrm{s}}$ and $\rho_{\mathrm{f}}$ and by the film thickness $t$. For a given frequency value $f$, the dependence of the surface wave phase velocity on these parameters may be represented by the dispersion relation [17]:

$c=f\left(E_{\mathrm{f}}, E_{\mathrm{s}}, \nu_{\mathrm{f}}, \nu_{\mathrm{s}}, \rho_{\mathrm{f}}, \rho_{\mathrm{s}}, t, f\right)$

Thus, for coated materials, the surface wave velocity turns out to depend on frequency. This phenomenon is called surface-wave dispersion. The kind of combination of film and substrate materials determines the character of this dependence-dispersion curve. If the film has a lower sound velocity than the substrate, the surface wave velocity decreases with increasing frequency (normal dispersion). In the reverse case, the surface wave velocity increases with increasing frequency (anomalous dispersion). The theoretical dispersion curve can be derived from the equation of elastic wave motion and the boundary conditions for traction forces and displacement $[18,19]$.

\subsection{Indentation testing: hardness and Young's modulus evaluation}

This method consists in making a small indentation in the film, recording the indentation load, $L$, and displacement, $h$, during one complete cycle of loading and unloading. The Young's modulus of the film, $E_{\mathrm{f}}$, is obtained by the slope of the initial portion of the unloading curve by adopting Sneddon's flat-ended cylinder punch model [20]. By equating the projected area in contact under the indenter to the area of the punch, they obtained for a Vickers indenter:

$S=\frac{\mathrm{d} L}{\mathrm{~d} h}=\left(\frac{2}{\pi}\right)^{1 / 2} D E_{r}$

where $S=\mathrm{d} L / \mathrm{d} h$, represents the initial unloading contact stiffness, which is the slope of the initial portion of the unloading curve, derived by linearly extrapolating the initial portion of the unloading curve to zero load [21] and $D$ is Vickers diagonal length. If we assume that the indenter had a pyramidal geometry and, instead of the diagonal length, using the term $h_{\mathrm{p}}$ that represents the plastic depth, corresponding to the depth at zero load after the referred linear fitting at the beginning of the unloading stage [22] we obtain:

$S^{-1}=\frac{\mathrm{d} h}{\mathrm{~d} L}=\frac{1}{2 h_{\mathrm{p}}}\left(\frac{\pi}{24.5}\right)^{1 / 2}\left(\frac{1}{E_{\mathrm{r}}}\right)$

$E_{\mathrm{r}}$ represents the reduced Young's modulus, which can be expressed by:

$\frac{1}{E_{\mathrm{r}}}=\frac{1-v_{\mathrm{f}}^{2}}{E_{\mathrm{f}}}+\frac{1-v_{\mathrm{i}}^{2}}{E_{\mathrm{i}}}$ 


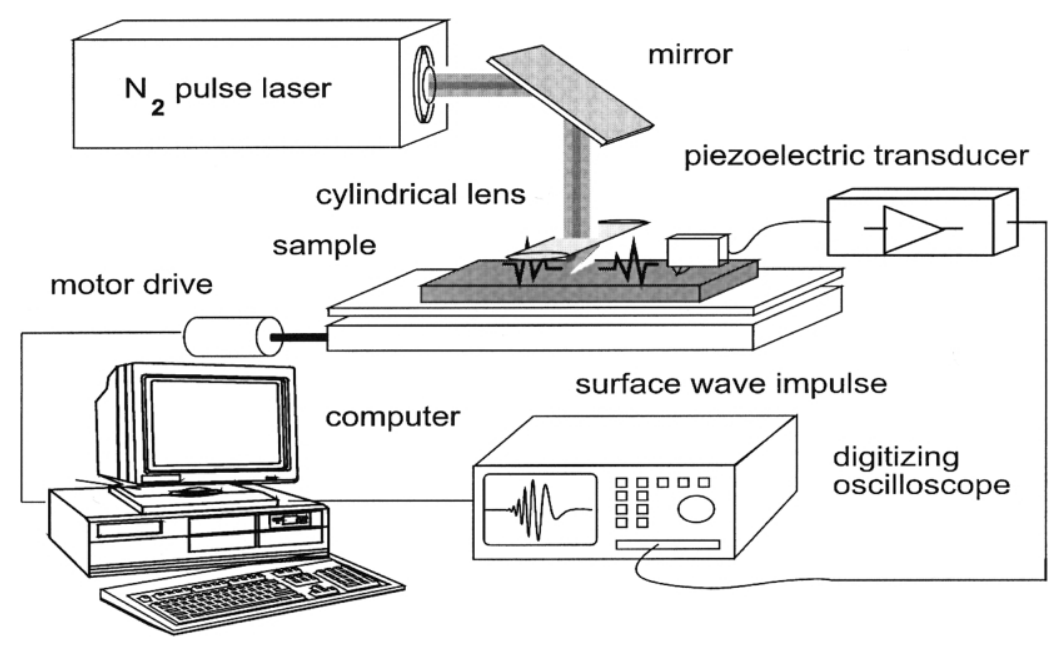

Fig. 1. Schematic representation of the surface wave equipment.

with $E_{\mathrm{f}}$ and $\nu_{\mathrm{f}}$ being the Young's modulus and Poisson's ratio for the film $\left(v_{\mathrm{f}}=0.25\right.$ [23] $)$ and $E_{\mathrm{i}}$ and $\nu_{\mathrm{i}}$, the same quantities for the diamond indenter $\left(E_{\mathrm{i}}=1141 \mathrm{GPa}\right.$ and $v_{\mathrm{i}}=0.07$ [23]). From this last relation it is then possible to determine the film's Young's modulus, $E_{\mathrm{f}}$.

\section{Experimental details}

\subsection{Sample preparation}

The $\mathrm{Ti}_{1-x} \mathrm{Si}_{x} \mathrm{~N}_{y}$ films were prepared in ALCATEL SCM650 equipment, on polished high-speed steel (AISI M2) and Si substrates, by reactive magnetron sputtering, from high purity $\mathrm{Ti}$ and $\mathrm{Si}$ elemental targets. The substrate holder was rotating over the targets at a constant speed of $4 \mathrm{rev}$. $/ \mathrm{min}$. The substrates were heated to $300{ }^{\circ} \mathrm{C}$ and d.c. biased from -75 up to $+25 \mathrm{~V}$. Titanium and silicon targets were coupled to r.f. sources $(13.56 \mathrm{MHz})$, with power in the range of $1.9-$ $3.2 \times 10^{4} \mathrm{~W} / \mathrm{m}^{2}$ for Ti and $0.4-2.6 \times 10^{4} \mathrm{~W} / \mathrm{m}^{2}$ for $\mathrm{Si}$. The depositions were conducted in an $\mathrm{Ar} / \mathrm{N}_{2}$ gas atmosphere, with a working pressure of approximately $0.4 \mathrm{~Pa}$ and a typical base pressure of $1 \times 10^{-4} \mathrm{~Pa}$. The atomic composition of the as-deposited films was measured by Rutherford backscattering spectrometry (RBS). An average number of five ball cratering (BC) experiments were carried out in each sample in order to extract film thickness $(t)$. The density of the films was estimated using the areal atomic density extracted from RBS measurements, divided by the thickness. X-Ray diffraction (XRD) experiments were carried out using a Philips PW 1710 apparatus $(\mathrm{CuK} \alpha$ radiation).

\subsection{Techniques for measuring the Young's modulus of the films}

\subsubsection{Surface acoustic wave equipment}

The basic device for SAW experiments is a pulsed nitrogen laser that is used to generate wide band surface wave pulses (wavelength: $337 \mathrm{~nm}$, pulse duration of 0.5 $\mathrm{ns})$. The pulse peak power was limited to $800 \mathrm{~kW}$, corresponding a pulse energy $(0.4 \mathrm{~mJ})$ low enough to avoid ablation of the film material. For the same reason, and to direct the acoustic wave propagation, the laser beam was focused into a line on the sample surface by a cylindrical lens. The heat energy of the laser pulse is absorbed within a small volume so quickly that a temperature gradient creates a sound impulse-acoustic wave. The surface wave impulse propagates perpendicular to the direction of the focal line along a distance $x$ and is detected by a piezoelectric transducer. The transducer consists of a metal wedge pressing a piezoelectric foil on the surface [24]. During the measuring procedure the distance between the laser focus line and the transducer is varied with a high degree of accuracy $(\Delta x=$ $\pm 1 \mu \mathrm{m})$, Fig. 1 [25].

To eliminate the unknown impulse response of the transducer, the difference method is used for measuring the phase velocity. Surface wave impulses are detected for at least two different distances, $x_{1}$ and $x_{2}$, from the transducer to the laser focus line. The surface wave velocity is obtained from the relation [26]:

$c(f)=\frac{\left(x_{2}-x_{1}\right) 2 \pi f}{\left[\phi_{2}\left(f, x_{2}\right)-\phi_{1}\left(f, x_{1}\right)\right]}$

where $\phi_{1}\left(f, x_{1}\right)$ and $\phi_{2}\left(f, x_{2}\right)$ are the surface wave phase values for frequency $f$ at positions $x_{1}$ and $x_{2}$, respectively. The phase spectra are obtained from a Fourier transformation of the surface-wave signals registered by the transducer at both distances and recorded with an oscilloscope.

The surface wave impulses can be seen as a superposition of harmonic surface waves of different frequencies. Since each wave propagates with its own velocity, the impulse form is broadened as the path increases. The impulse deformation contains important information 
Table 1

Composition, grain size, thickness and density of the samples produced at different bias voltages

\begin{tabular}{|c|c|c|c|c|c|c|c|}
\hline Sample & $\begin{array}{l}\mathrm{Ti} \\
\text { (at.\%) }\end{array}$ & $\begin{array}{l}\mathrm{Si} \\
\text { (at.\%) }\end{array}$ & $\begin{array}{l}\mathrm{N} \\
\text { (at.\%) }\end{array}$ & $\begin{array}{l}\text { Bias voltage } \\
\text { (V) }\end{array}$ & $\begin{array}{l}\text { Grain size } \\
(\mathrm{nm})\end{array}$ & $\begin{array}{l}\text { Thickness } \\
(\mu \mathrm{m})\end{array}$ & $\begin{array}{l}\text { Density } \\
\left(\mathrm{g} / \mathrm{cm}^{3}\right)\end{array}$ \\
\hline $\mathrm{Ti}_{.87} \mathrm{Si}_{.13} \mathrm{~N}_{1.04}$ & 42.6 & 6.4 & 51 & -75 & 5.5 & 1.3 & 4.4 \\
\hline $\mathrm{Ti}_{.78} \mathrm{Si}_{.22} \mathrm{~N}_{1.07}$ & 37.7 & 10.6 & 51.7 & -50 & 8.5 & 2.2 & 4.5 \\
\hline $\mathrm{Ti}_{.83} \mathrm{Si}_{.17} \mathrm{~N}_{1.06}$ & 40.3 & 8.3 & 51.4 & -25 & 7 & 1.5 & 4.7 \\
\hline $\mathrm{Ti}_{.83} \mathrm{Si}_{.17} \mathrm{~N}_{1.06}$ & 40.3 & 8.3 & 51.4 & 0 & 23 & 1.3 & 5.1 \\
\hline $\mathrm{Ti}_{.78} \mathrm{Si}_{.22} \mathrm{~N}_{1.07}$ & 37.7 & 10.6 & 51.7 & 15 & 25 & 1.9 & 4.0 \\
\hline $\mathrm{Ti}_{.80} \mathrm{Si}_{.20} \mathrm{~N}_{1.07}$ & 38.6 & 9.7 & 51.7 & 25 & 34 & 1.7 & 3.4 \\
\hline
\end{tabular}

about the film material, including the Young's modulus. In a homogeneous (uncoated) material, the same impulse shape would be detected in $x_{1}$ and $x_{2}$.

Inserting the spectra phase into Eq. (6) yields the phase velocity of the surface wave as a function of the frequency. For that purpose, the inverse solution of the surface wave dispersion, given in general form in Eq. (2), has to be found. A non-linear regression is used, which can be obtained by the principle of minimising the least-square error [27]:

$\sum_{k}\left[c(f)-c\left(E_{\mathrm{s}}, E_{\mathrm{f}}, \nu_{\mathrm{s}}, \nu_{\mathrm{f}}, \rho_{\mathrm{s}}, \rho_{\mathrm{f}}, t, f\right)\right] \rightarrow \min$

The first term in Eq. (7) is the measured surfacewave velocity spectrum, $c(f)$, and the second term represents the theoretical dispersion curve obtained numerically from the boundary conditions [18]. The kind of material and the bandwidth of the measurement determine how many of the seven parameters in Eq. (7) can be obtained [28]. This model was extended for samples with more than one layer [29]. Since most of our samples where prepared with a $\mathrm{Ti}$ interlayer, we needed to introduce into the fit program the parameters of this additional layer (thickness, Young's modulus, Poisson's ratio and density).

\subsubsection{Ultramicroindentation set-up}

The ultramicroindentation tests were performed in a computer-controlled Fischerscope H100 tester, equipped with a quadrangular pyramidal Vickers diamond indenter. The applied load was increased in 60 steps until nominal load reached $30 \mathrm{mN}$, which was the maximum load in all tests. As a rule of thumb, the indentation depths did not exceed one-tenth of the coating thickness. The system has a load resolution better than $1 \mu \mathrm{N}$ and the range of the nominal test load is between $4 \mathrm{mN}$ and $1 \mathrm{~N}$. To extract an average value of the Young's modulus, 20 indentations were performed in each sample, and the error extracted for the standard deviation. In order to achieve reasonable accurate depth values, two main corrections were taken into consideration: the calibration of the thermal drift and the calibration of the indenter offset $[10,22]$.

\section{Results and discussion}

RBS analyses showed that coatings are almost stoichiometric. The nitrogen atomic composition was evaluated within an error of approximately 3 at.\%. The error in the $\mathrm{Si}$ to $\mathrm{Ti}$ composition ratio ([Si]/[Ti]) was lower than 0.02 . Oxygen was not detectable by RBS in the as-deposited samples, which means that its content is less than approximately 2 at.\%. An error of approximately $0.1 \mu \mathrm{m}$ was estimated for thickness values uncertainty (maximum deviation to the average) and for the areal atomic density, extracted from RBS measurements, an error of 5\% was assumed. Thus, an error between $7 \%$ and $13 \%$ for density values was obtained. Atomic composition, thickness, density as well as the grain size are presented in Tables 1 and 2. Further information on the as-deposited samples can be found elsewhere [10]. Density values, estimated as described above (see Section 3.1), are between 3.4 and $5.1 \mathrm{~g} /$ $\mathrm{cm}^{3}$. For the TiN sample the value found was $4.9 \mathrm{~g} /$ $\mathrm{cm}^{3}$, which is smaller than that of TiN bulk value $(\rho=$ $\left.5.4 \mathrm{~g} / \mathrm{cm}^{3}[30]\right)$.

Table 2

Composition, grain size, thickness and density of the samples produced at the same bias voltage $(-50 \mathrm{~V})$

\begin{tabular}{lllllll}
\hline Sample & $\begin{array}{l}\mathrm{Ti} \\
(\text { at.\% })\end{array}$ & $\begin{array}{l}\mathrm{Si} \\
(\text { at. } \%)\end{array}$ & $\begin{array}{l}\mathrm{N} \\
(\text { at. } \%)\end{array}$ & $\begin{array}{l}\text { Grain size } \\
(\mathrm{nm})\end{array}$ & $\begin{array}{l}\text { Thickness } \\
(\mu \mathrm{m})\end{array}$ \\
\hline $\mathrm{TiN}$ & 50 & - & 50 & 8 & $\begin{array}{l}\text { Density } \\
\left(\mathrm{g} / \mathrm{cm}^{3}\right)\end{array}$ \\
$\mathrm{Ti}_{.95} \mathrm{Si}_{.05} \mathrm{~N}_{1.02}$ & 47 & 2.5 & 50.5 & 8 & 3.5 & 4.7 \\
$\mathrm{Ti}_{.88} \mathrm{Si}_{.12} \mathrm{~N}_{1.04}$ & 43.1 & 5.9 & 51 & 7 & 2.2 & 4.9 \\
$\mathrm{Ti}_{.85} \mathrm{Si}_{.15} \mathrm{~N}_{1.03}$ & 41.9 & 7.4 & 50.7 & 6 & 2.1 & 4.8 \\
$\mathrm{Ti}_{.78} \mathrm{Si}_{.22} \mathrm{~N}_{1.07}$ & 37.7 & 10.6 & 51.7 & 6 & 3.2 \\
$\mathrm{Ti}_{.63} \mathrm{Si}_{.37} \mathrm{~N}_{1.12}$ & 29.7 & 17.5 & 52.8 & 6 & 4.5 \\
\hline
\end{tabular}



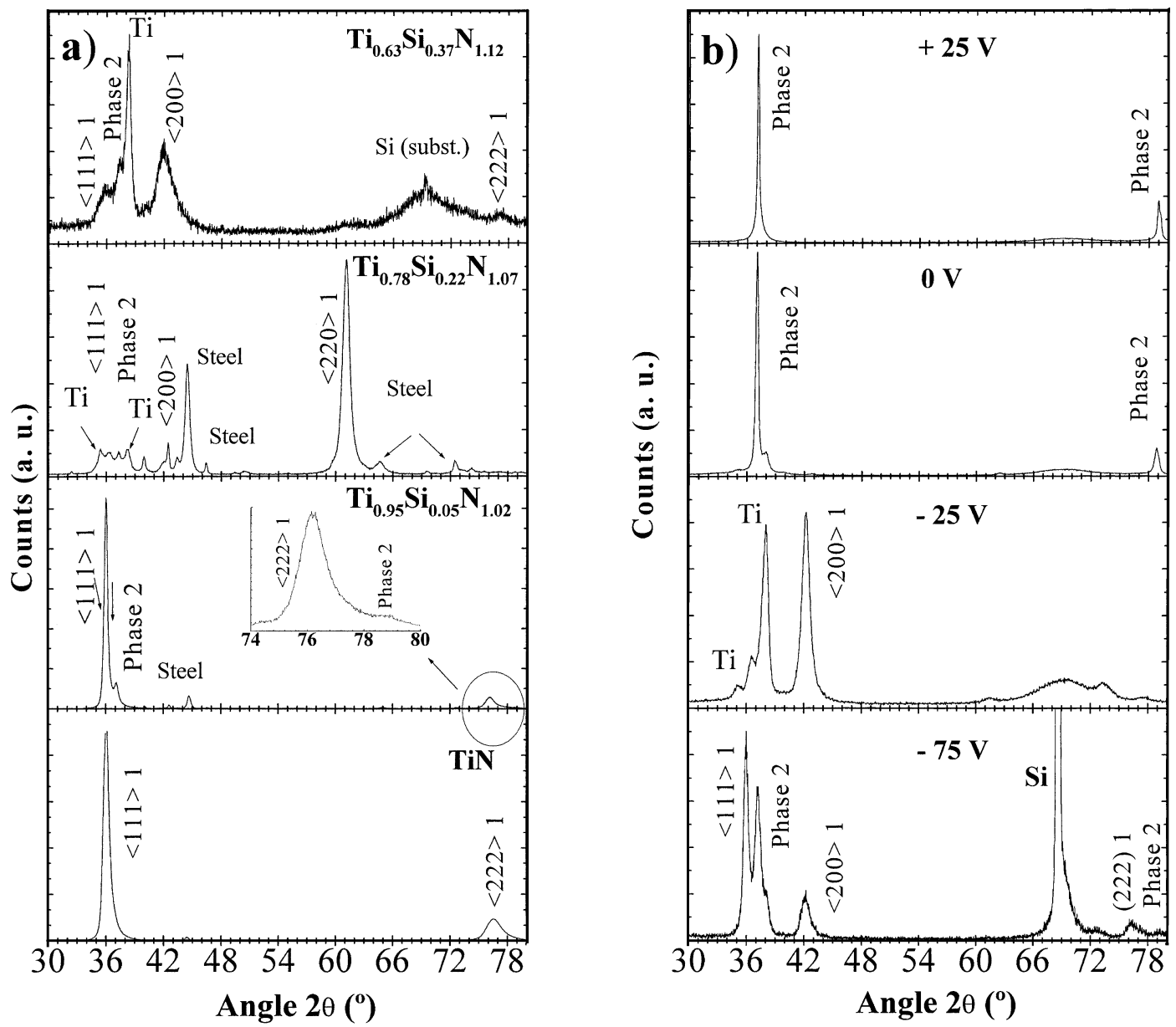

Fig. 2. X-Ray diffraction patterns of $\mathrm{Ti}_{1-x} \mathrm{Si}_{x} \mathrm{~N}_{y}$ films as a function of: (a) Si content and, (b) applied bias voltage $(-75$ to $+25 \mathrm{~V})$. TiN phase is referred as phase 1 and the $(\mathrm{Ti}, \mathrm{Si}) \mathrm{N}$ metastable phase as phase 2 .

\subsection{Structural characterisation}

XRD patterns illustrated in Fig. 2 revealed the presence of 2 crystalline phases, where phase 1 (lattice parameter of approx. $0.429 \mathrm{~nm}$ ) can be assigned to a cubic $\mathrm{B} 1 \mathrm{NaCl}$ type structure, typical for TiN, and phase 2 is also a face centred cubic (fcc) type structure, but with a smaller lattice parameter $(\sim 0.418 \mathrm{~nm})$. Without ion bombardment, only phase 2 is developed, which corresponds to a metastable $(\mathrm{Ti}, \mathrm{Si}) \mathrm{N}$ phase where $\mathrm{Si}$ atoms are occupying $\mathrm{Ti}$ positions, which explains the low value of the lattice parameter. Transmission electron microscopy (TEM) experiments confirmed the fcc type structure for that metastable phase $[31,32]$. The presence of phase 1, suggests the formation of a system where the segregation of $\mathrm{TiN}$ and $\mathrm{Si}_{3} \mathrm{~N}_{4}$ phases already occurred. The higher lattice parameter of phase 1 $(\sim 0.429 \mathrm{~nm})$ when compared with that of bulk TiN $(0.424 \mathrm{~nm})$, could be explained by taking into account the effect of the high stress levels in these samples on peak positions $(\sim 1 \%$ decrease $)$.
Some of XRD patterns displayed in Fig. 2 revealed a mixture of the metastable phase with nanocomposite coating phases, which indicates that, in general, the segregation of TiN and $\mathrm{Si}_{3} \mathrm{~N}_{4}$ phases is not complete. This means that a nanocomposite of the type nc-TiN/ nc- $(\mathrm{Ti}, \mathrm{Si}) \mathrm{N} / \mathrm{a}-\mathrm{Si}_{3} \mathrm{~N}_{4}$ is probably present, although the presence of $\mathrm{Si}_{3} \mathrm{~N}_{4}$ is difficult to be demonstrated. The relative amount of the $\mathrm{TiN}$ and $(\mathrm{Ti}, \mathrm{Si}) \mathrm{N}$ phases is dependent of Si content and deposition parameters. For example, in samples with approximately 14 at.\% Si, prepared at low substrate temperature $\left(200{ }^{\circ} \mathrm{C}\right)$, the metastable $(\mathrm{Ti}, \mathrm{Si}) \mathrm{N}$ phase is the most significant phase, but with the increase in temperature (until $500{ }^{\circ} \mathrm{C}$ ) this phase disappeared from the $\mathrm{X}$-ray diffraction pattern [32].

\subsection{Young's modulus evaluation}

Fig. 3 shows examples of surface acoustic wave impulses detected on high-speed steel substrates, coated with $\mathrm{Ti}_{0.95} \mathrm{Si}_{0.05} \mathrm{~N}_{1.02}(2.5$ at.\% $\mathrm{Si})$, for the distances $x_{1}$ 


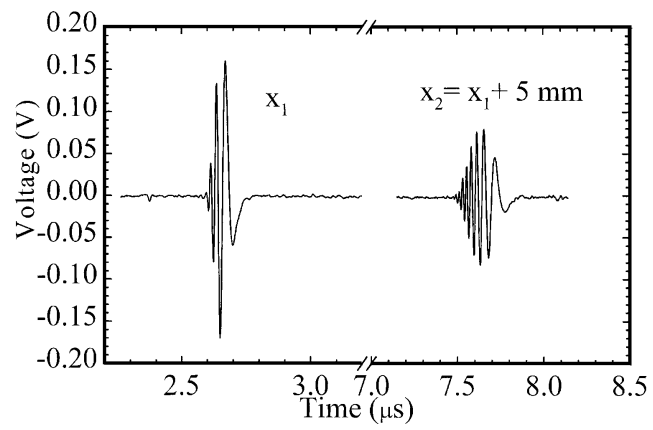

Fig. 3. Surface wave impulse detected on steel coated with $\mathrm{Ti}_{0.83} \mathrm{Si}_{0.17} \mathrm{~N}_{1.06}$ at a distance: (a) $x_{1}$ and (b) $x_{2}=x_{1}+0.005 \mathrm{~m}$; between the laser focus line and detector.

and $x_{2}=x_{1}+5 \mathrm{~mm}$, between the laser focus line and transducer. The observed changes of the impulse shape reveal that the surface-wave propagation is dispersive. Fig. 4 shows the phase spectra of these signals. The phase plot of the signal detected at $x_{1}$ has been taken as a reference $\left[\phi_{1}\left(f, x_{1}\right)\right]$ and so the phase plot for $x_{2}$ reveals the effect of the wave propagation from $x_{1}$ to $x_{2}$. The corresponding spectrum of phase velocity of surface waves as a function of frequency, obtained from inserting the phase spectra into Eq. (6) is represented by the continuous curve in Fig. 5. Only the results in the frequency range of $10-50 \mathrm{MHz}$ were used. For lower frequencies the acoustic wavelength gets the dimension of the sample thickness and plate modes propagates instead of the Rayleigh modes, which must be excluded from the fit procedure. However, at higher frequencies the attenuation due to the scattering of the acoustic waves by the steel substrate reduces the signal/ noise ratio below an acceptable limit. This implied that, in our case, only one parameter of the film material could be obtained, e.g. the Young's modulus $E_{\mathrm{f}}$, from the adjustment between the measured and calculated phase velocity spectra (Fig. 5). The Poisson's ratio, density and thickness of the film material had to be inserted for the fitting procedure. We used for the Poisson's ratio $\nu_{\mathrm{f}}=0.25$ [23]. The effect of the Poisson's ratio on the $E_{\mathrm{f}}$ result can be neglected, however, the density $\left(\rho_{\mathrm{f}}\right)$ and the thickness $(t)$ values have a proportional influence on the fitting result for $E_{\mathrm{f}}$. Thus, the error for the calculated Young's modulus $E_{\mathrm{f}}$ can be estimated as $\left|\Delta E_{\mathrm{f} \mathrm{sAw}} / E_{\mathrm{f} \mathrm{sAw}}\right|=|\Delta t / t|+\left|\Delta \rho_{\mathrm{f}} / \rho_{\mathrm{f}}\right|$. The anomalous dispersion suggests a higher sound velocity for $\mathrm{Ti}_{1-x} \mathrm{Si}_{x} \mathrm{~N}_{y}$ films compared with the substrate.

For a better comparative evaluation of the Young's modulus obtained by both techniques, the samples were divided in two distinct groups, according to their preparation procedure. The samples in the first group were prepared with constant deposition parameters $\left(300{ }^{\circ} \mathrm{C}\right.$ deposition temperature, $\mathrm{Ti}$ and $\mathrm{Si}$ power densities of $1.91 \times 10^{4} \mathrm{~W} / \mathrm{m}^{2}$ and $0.78 \times 10^{4} \mathrm{~W} / \mathrm{m}^{2}$, respectively, an

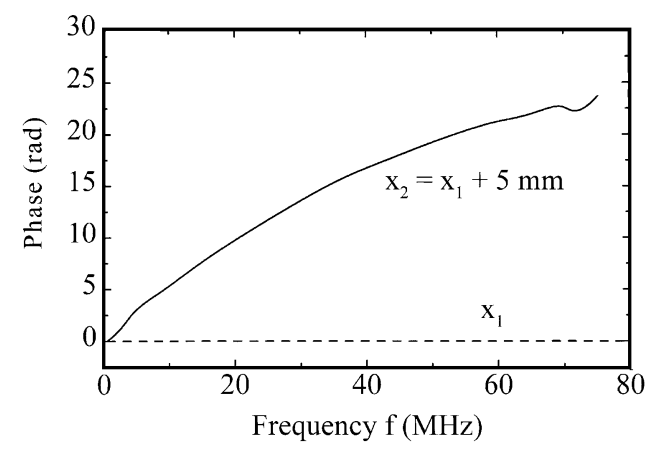

Fig. 4. Phase spectra of surface-wave impulse received at different distances $x$ between the laser focus line and transducer.

argon flux of $100 \mathrm{sccm}$ and nitrogen flux of $5 \mathrm{sccm}$ ), and by varying the applied bias voltage from $-75 \mathrm{~V}$ to $+25 \mathrm{~V}$. The second group includes the samples, whose films were grown with the same bias voltage $(-50 \mathrm{~V})$, temperature $\left(300{ }^{\circ} \mathrm{C}\right)$ and working gas flux $(100 \mathrm{sccm})$, but with different $\mathrm{Ti} / \mathrm{Si}$ target power combinations. The $\mathrm{N}_{2}$ flux was adjusted in order to control the nitrogen content close to the stoichiometric condition. Fig. 6a,b presents the variation of Young's modulus for the two groups of samples obtained by the two methods.

The first note that arises from the observation of the two graphs is that Young's moduli measured by both test methods show a similar dependence on bias voltage and $\mathrm{Si}$ content. A fairly good agreement is observed for the samples of first group (variation in the bias voltage, Fig. 6a), excluding the sample prepared with a bias voltage of $-50 \mathrm{~V}$.

Young's modulus as a function of Si content obtained by the SAW method, showed that no significant changes are observed with its increase (Fig. 6b). $E_{\mathrm{f}}$ values between 300 and $340 \mathrm{GPa}$ were obtained, except for the sample with the highest $\mathrm{Si}$ content, where some slight decrease was observed. However, the indentation method showed a few variations, especially in the samples with intermediate Si contents: 7.4-10.6 Si at.\%, corresponding to the region where highest hardness values were

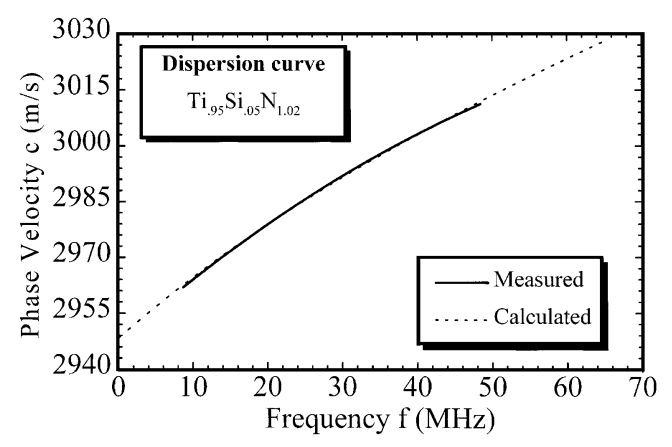

Fig. 5. Surface wave phase velocity c, as a function of frequency $f$ measured in $\mathrm{Ti}_{0.95} \mathrm{Si}_{0.05} \mathrm{~N}_{1.02}$-coated high-speed steel. 

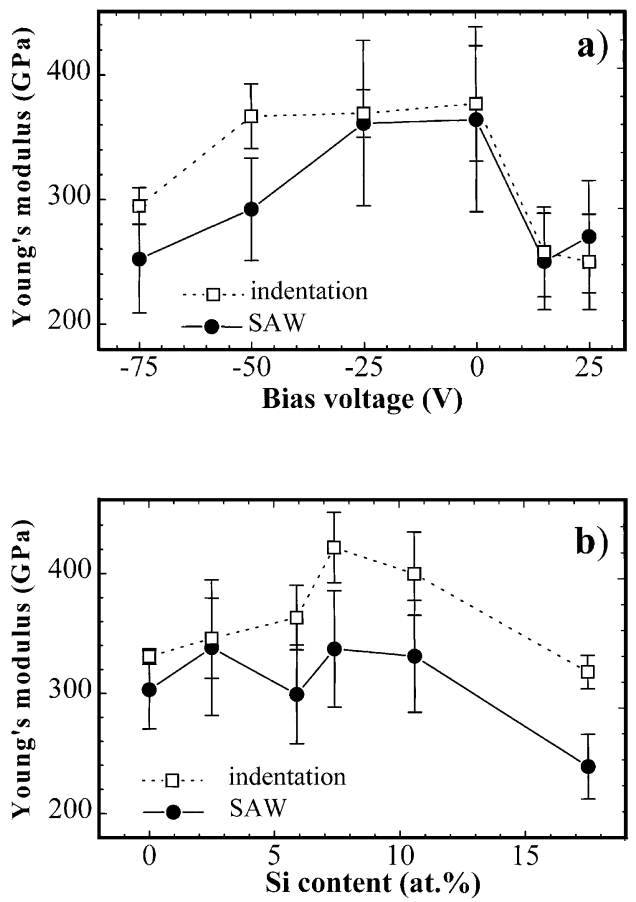

Fig. 6. Young's modulus of $\mathrm{Ti}_{1-x} \mathrm{Si}_{x} \mathrm{~N}_{y}$ films as a function of: (a) the applied bias voltage (Table 1) and, (b) the Si content (Table 2).

obtained, with a maximum value close to $47 \mathrm{GPa}$ [10] (Si content of 7.4 at.\%). Within this region, $E_{\mathrm{f}}$ values in the order of $400 \mathrm{GPa}$ were obtained.

A few facts may explain the small differences between the results given by the two techniques. First of all, it should be pointed out that the results obtained with the SAW method show a correlation with the density of the material. A density dependence of Young's modulus following the relation $E=E_{0}\left(\rho / \rho_{0}\right)^{m}$ where $m$ is between 3 and 4 was already reported [33], and similar dependence was obtained by other authors [34,35]. Apart from the decrease of the density, typically observed in sputtered thin films as compared with the bulk material [36], there is also a variation of the density with the $\mathrm{Si}$ content (for a Si content of 2.5 at.\% a density of $4.9 \mathrm{~g} / \mathrm{cm}^{3}$ was observed, while for a $\mathrm{Si}$ content of 17.5 at. $\left.\%, \rho=4 \mathrm{~g} / \mathrm{cm}^{3}\right)$. We note that for high density values $\left(\geq 4.9 \mathrm{~g} / \mathrm{cm}^{3}\right)$ the Young's modulus obtained by both techniques is very similar. It was found that the low density of several films was not sensitively indicated by the microindentation technique [34,37]. The films have a columnar structure, which suggests that their macroscopic elastic behaviour is anisotropic. However, pores between the columns may be supposed to have a long-stretched shape and to be preferentially oriented perpendicular to the surface and, therefore, may cause an additional anisotropy. This would result in different Young's moduli parallel and perpendicular to the film. It cannot be excluded that indentation and laser-acoustic test methods yield different results for an anisotropic film due to the different deformation state they create in the test material. The loading by the indenter is perpendicular to the surface and can be assumed to indicate the elastic deformation of the lattice planes preferentially oriented into the perpendicular direction. The propagation of the surface acoustic waves causes the volume elements to circulate with a displacement much smaller compared with the indentation test on an elliptically shaped course. The information this wave modes provides can be supposed to reveal more the averaged elastic behaviour of the material for all directions.

Apart form the effect of the anisotropy, the experience has shown that the indentation method yields higher elastic moduli than the laser acoustic technique for porous materials [38]. Only few percent porosity formed as a network of long-stretched nearly crack-like pores reduced the elastic modulus of the $\mathrm{ZrO}_{2}$ plasma-sprayed coatings to approximately $30 \mathrm{GPa}$ compared with 240 GPa tabulated for the bulk ceramic material [39].

The microindentation technique may give Young's modulus values that correspond to the film material and are almost independent of the porosity, while the SAW results provide an effective modulus averaging the effect of both matrix (bulk material) and defects or voids. This may explain why the indentation results are systematically higher than SAW ones. With a low porosity level we have higher density values, and in these cases the results of both methods are indeed closer. However, this porosity-density correlation and the anisotropy induced by columnar structure are not enough to explain all the differences, since there is a good agreement between both methods for some low densities values $\left(3.4 \mathrm{~g} / \mathrm{cm}^{3}\right.$ and $\left.4.0 \mathrm{~g} / \mathrm{cm}^{3}\right)$, and distinct behaviours were found for samples with similar density $(4.8$ and $4.9 \mathrm{~g} /$ $\mathrm{cm}^{3}$ ). It should be taken in consideration that samples with lowest density values were prepared with positive bias, which usually results in coatings with low values of hardness and Young's modulus. These films only revealed the presence of the metastable $(\mathrm{Ti}, \mathrm{Si}) \mathrm{N}$ phase and also presented relatively high grain sizes. The other samples with relatively low densities were prepared with different conditions (one with a bias of $-75 \mathrm{~V}$ and the other with a bias of $-50 \mathrm{~V}$ and the highest Si content) and in both cases a mixture of TiN and metastable $(\mathrm{Ti}, \mathrm{Si}) \mathrm{N}$ phases is present.

However, the TiN samples and the film with 2.5 at. $\%$ $\mathrm{Si}$ also revealed relatively higher grain sizes and only one phase is present. A good agreement was found between results from the two techniques.

However, the group of samples with higher Si contents (Fig. 6b) shows a discrepancy that, although justifiable by the density, columnar structure or preferred growth orientation, may also be attributed to a distinct microstructure. The presence of $\mathrm{Si}$ atoms induced the formation of a nanocomposite material consisting of 
TiN and $(\mathrm{Ti}, \mathrm{Si}) \mathrm{N}$ nanocrystallites and eventually a $\mathrm{SiN}_{x}$ amorphous phase. The grain size decreases with the increase of the Si concentration (see Table 2). In case of sufficiently high surface mobility, the segregated Si can be enough for the nucleation and development of $\mathrm{Si}_{3} \mathrm{~N}_{4}$ phase, which limits the growth of the $\mathrm{TiN}$ nanocrystallites. These components have distinctly different elastic properties, which can justify a distinct response of the material when subjected to a different kind of solicitation. The indentation and SAW measurements induce different amplitude of elongation of the material. During indentation the material is elongated above the limit of plastic deformation. However, the extension of the atoms displacement induced by SAW is in the range of the inter-atomic distance.

From the obtained results, it is clear that the conjugation of the two referred methods is important to better characterise the Young's modulus of a thin film. The differences between the values obtained by the two methods can be due to several factors where the kind of film microstructure plays an important role. The effect of the Si content is somewhat difficult to specify, but as it increases, the differences in the results of Young's modulus obtained by the two techniques becomes more important, at least when the surface mobility is enough for the development of the nanocomposite material. The presence of the $\mathrm{TiN}$ and $(\mathrm{Ti}, \mathrm{Si}) \mathrm{N}$ phases and the possible amorphous silicon nitride phase, is the main issue here.

\section{Summary and conclusions}

XRD patterns revealed the presence of two crystalline phases, where phase 1 (lattice parameter of approx. $0.429 \mathrm{~nm}$ ) can be assigned to a cubic $\mathrm{B} 1 \mathrm{NaCl}$ type structure, typical for TiN, and phase 2 is also a fcc type structure, but with a smaller lattice parameter $(\sim 0.418$ $\mathrm{nm})$. Both XRD and TEM results, indicated that phase 2 is a cubic lattice, corresponding to a metastable (Ti,Si)N phase where $\mathrm{Si}$ atoms would be occupying Ti positions, which explains the low value of the lattice parameter. The presence of the crystalline TiN, suggests the formation of a system where a segregation of TiN and $\mathrm{Si}_{3} \mathrm{~N}_{4}$ phases already occurred. Some of XRD patterns revealed a mixture of the metastable phase with nanocomposite coating phases, which indicates that, in general, the segregation of $\mathrm{TiN}$ and $\mathrm{Si}_{3} \mathrm{~N}_{4}$ phases is not complete, leading to the development of a nanocomposite film of the type nc-TiN/nc- $(\mathrm{Ti}, \mathrm{Si}) \mathrm{N} / \mathrm{a}-\mathrm{Si}_{3} \mathrm{~N}_{4}$. Regarding the results of Young's modulus evaluation, both mechanical test methods laser-acoustics and indentation revealed similar variation tendencies with bias voltage and Si content. SAW results seem to indicate no apparent dependency of film Young modulus on $\mathrm{Si}$, except for high Si contents. A good agreement was found between results from the two techniques for samples that revealed one phase much more important than the other and a grain size also relatively higher, which is related with higher degree of crystallinity. However, for samples where the mixture of TiN and $(\mathrm{Ti}, \mathrm{Si}) \mathrm{N}$ phases is present the indentation method showed relatively higher values. In these samples the grain size is lower, which results in a higher volume fraction of grain boundaries. The reasons for these differences are not yet well understood, but they are certainly related with the limits of validity of each of the two methods, which are connected with a distinct response of the nanocomposite material when subjected to a different kind of solicitation. However, the different textures, microstructure, density and correlated porosity also have some influence.

The use of these two techniques and the clarification of the discrepancies that might be revealed, are surely important for a better understanding of either physical and/or mechanical behaviours which depend on Young's modulus characterisation.

\section{Acknowledgments}

The authors gratefully acknowledge the financial support of the 'Fundação para a Ciência e a Tecnologia' (FCT) institution by the project no. POCTI/32670/ CTM/2000 co-financed by European community fund FEDER, as well as the financial support of the German/ Portuguese DAAD/ICCTI institutions. A.P. also acknowledges a fellowship from FCT during the course of this work.

\section{References}

[1] M. Nastasi, D.M. Parkin, H. Gleiter (Eds.), Mechanical Properties and Deformation Behaviour of Materials Having UltraFine Microstructures, NATO ASI Series, 233, Kluwer, Dordrecht, 1993.

[2] A.S. Edelstein, R.C. Cammarata, Nanomaterials: Synthesis, Properties and Applications, Institute of Physics, Bristol, 1996.

[3] S. Veprek, Crit. Rev. J. Vac. Sci. Technol. A 17 (1999) 2401.

[4] J. Musil, Surf. Coat. Technol. 125 (2000) 322.

[5] S. Veprek, Surf. Coat. Technol. 97 (1997) 15, and references therein.

[6] H. Gleiter, Prog. Mater. Sci. 33 (1989) 223.

[7] J.S. Reid, X. Sun, E. Kolawa, M.A. Nicolet, IEEE Electron. Device Lett. 15 (1994) 298.

[8] T. Hirai, S. Hayashi, J. Mater. Sci. 17 (1982) 1320.

[9] L. Shizhi, S. Yulong, P. Hongrui, Plasma Chem. Plasma Process. 12 (1992) 287.

[10] F. Vaz, L. Rebouta, S. Ramos, M.F. da Silva, J.C. Soares, Surf. Coat. Technol. 108/109 (1998) 236.

[11] C. Louro, A. Cavaleiro, Surf. Coat. Technol. 123 (2000) 192.

[12] M. Diserens, J. Patscheider, F. Lévy, Surf. Coat. Technol. 108/ 109 (1998) 241.

[13] S. Christiansen, M. Albrecht, H.P. Strunk, S. Veprek, J. Vac. Sci. Technol. B 16 (1998) 19.

[14] X. Sun, J.S. Reid, E. Kolawa, M.-A. Nicolet, J. Appl. Phys. 81 (1997) 656.

[15] D. Schneider, T. Schwarz, Surf. Coat. Technol. 91 (1997) 136. 
[16] B.A. Auld, Acoustic Fields and Waves in Solids, 1,, Krieger, Florida, 1973, p. 82

[17] B.A. Auld, Acoustic Fields and Waves in Solids, 2,, Krieger, Florida, 1973, p. 92.

[18] G.W. Farnell, F.L. Adler, in: W.P. Mason, R.N. Thurston (Eds.), Physical Acoustics, 6, Academic Press, New York, 1970, p. 37.

[19] G.W. Farnell, F.L. Adler, in: W.P. Mason, R.N. Thurston (Eds.), Physical Acoustics, 9, Academic Press, New York, 1972, p. 93.

[20] I.N. Sneddon, Int. J. Eng. Sci. 3 (1965) 47.

[21] G.M. Pharr, W.C. Oliver, MRS Bull. 7 (1992) 28.

[22] A.C. Trindade, A. Cavaleiro, J.V. Fernandes, J. Test. Eval. 22 (4) (1994) 365 .

[23] E. Török, A.J. Perry, L. Chollet, W.D. Sproul, Thin Solid Films 153 (1987) 37

[24] H. Coufal, R. Grugier, P. Hess, A. Neubrand, J. Acoust. Am. Soc. 92 (1992) 2980.

[25] D. Schneider, T. Schwarz, B. Schultrich, Thin solid Films 219 (1992) 92.

[26] D. Schneider, T. Schwarz, H.-J. Scheibe, M. Panzner, Thin Solid Films 295 (1997) 107.

[27] D.W. Marquadt, J. Soc. Indust. Math. 2 (1963) 431.
[28] D. Schneider, H. Ollendorf, T. Schwarz, Appl. Phys. A 61 (1995) 277.

[29] D. Schneider, B. Schultrich, H.-J. Scheibe, H. Ziegele, M. Griepentrog, Thin Solid Films 332 (1998) 157.

[30] J.-E. Sundgren, Thin Solid Films 128 (1985) 21.

[31] F. Vaz, L. Rebouta, P. Goudeau, J. Pacaud, H. Garem, J.P. Rivière, A. Cavaleiro, E. Alves, Surf. Coat. Technol. 133/134 (2000) 307.

[32] F. Vaz, L. Rebouta, B. Almeida, P. Goudeau, J. Pacaud, J.P. Rivière, J. Bessa e Sousa, Surf. Coat. Technol. 120/121 (1999) 166.

[33] C. Jin, J.D. Luttmer, D.M. Smith, T.A. Ramos, MRS Bull. 22 (1997) 39.

[34] S. Carvalho, F. Vaz, L. Rebouta, D. Schneider, A. Cavaleiro, E. Alves, Surf. Coat. Technol. 142/144 (2001) 110.

[35] F. Cracium, G. Guidarelli, C. Galassi, E. Roncari, Ultrasonics 36 (1998) 427.

[36] M. Ohring, The Materials Science of Thin Films, Academic Press, San Diego, 1992.

[37] L. Rebouta, C.J. Tavares, R. Aimo, Z. Wang, K. Pischow, E. Alves, T.C. Rojas, J.A. Odriozola, Surf. Coat. Technol. 133/ 134 (2000) 234.

[38] M. Griepentrog, BAM Berlin, private communication.

[39] D. Schneider, Th. Schwarz, H.-P. Buchkremer, D. Stöver, Thin Solid Films 224 (1993) 177. 